\title{
Comparative study of cytotoxic effects induced by environmental genotoxins using XPC- and CSB-deficient human lymphoblastoid TK6 cells
}

Akira Sassa ${ }^{{ }^{*}}$, Takayuki Fukuda ${ }^{2}$, Akiko Ukai ${ }^{3}$, Maki Nakamura², Michihito Takabe², Takeji Takamura-Enya ${ }^{4}$, Masamitsu Honma ${ }^{3}$ and Manabu Yasui ${ }^{3^{*}}$

\begin{abstract}
Background: The human genome is constantly exposed to numerous environmental genotoxicants. To prevent the detrimental consequences induced by the expansion of damaged cells, cellular protective systems such as nucleotide excision repair (NER) exist and serve as a primary pathway for repairing the various helix-distorting DNA adducts induced by genotoxic agents. NER is further divided into two sub-pathways, namely, global genomic NER (GG-NER) and transcription-coupled NER (TC-NER). Both NER sub-pathways are reportedly involved in the damage response elicited by exposure to genotoxins. However, how disruption of these sub-pathways impacts the toxicity of different types of environmental mutagens in human cells is not well understood.
\end{abstract}

Results: To evaluate the role of NER sub-pathways on the cytotoxic effects of mutagens, we disrupted XPC and CSB to selectively inactivate GG-NER and TC-NER, respectively, in human lymphoblastoid TK6 cells, a standard cell line used in genotoxicity studies. Using these cells, we then comparatively assessed their respective sensitivities to representative genotoxic agents, including ultraviolet C (UVC) light, benzo [a] pyrene (B(a)P), 2-amino-3,8-dimethylimidazo [4,5-f] quinoxaline (MelQx), 2-amino-1-methyl-6-phenylimidazo [4,5-b] pyridine (PhIP), $\gamma$-ray, and 2-acetylaminofluorene (2AAF). $\mathrm{CSB}^{-/-}$cells exhibited a hyper-sensitivity to UVC, B(a)P, and MelQx. On the other hand, XPC ${ }^{--}$cells were highly sensitive to UVC, but not to B(a)P and MelQx, compared with wild-type cells. In contrast with other genotoxins, the sensitivity of $X \mathrm{XC}^{-1-}$ cells against PhIP was significantly higher than $\mathrm{CSB}^{-1-}$ cells. The toxicity of $\mathrm{Y}^{\text {-ray }}$ and 2-AAF was not enhanced by disruption of either XPC or CSB in the cells.

Conclusions: Based on our findings, genetically modified TK6 cells appear to be a useful tool for elucidating the detailed roles of the various repair factors that exist to combat genotoxic agents, and should contribute to the improved risk assessment of environmental chemical contaminants.

Keywords: Nucleotide excision repair, XPC, CSB, Environmental mutagen, Cytotoxicity, TK6

\footnotetext{
* Correspondence: a-sassa@chiba-u.jp; m-yasui@nihs.go.jp

1 Department of Biology, Graduate School of Science, Chiba University, Chiba

263-8522, Japan

${ }^{3}$ Division of Genetics and Mutagenesis, National Institute of Health Sciences,

3-25-26 Tonomachi, Kawasaki-ku, Kawasaki 210-9501, Japan

Full list of author information is available at the end of the article
}

C The Author(s). 2019 Open Access This article is distributed under the terms of the Creative Commons Attribution 4.0 International License (http://creativecommons.org/licenses/by/4.0/), which permits unrestricted use, distribution, and reproduction in any medium, provided you give appropriate credit to the original author(s) and the source, provide a link to the Creative Commons license, and indicate if changes were made. The Creative Commons Public Domain Dedication waiver (http://creativecommons.org/publicdomain/zero/1.0/) applies to the data made available in this article, unless otherwise stated. 


\section{Introduction}

Cellular DNA is continuously exposed to various environmental agents such as ultraviolet (UV) light from the sun, ionizing radiation, chemical compounds found in foods, and endogenous oxidative stress. This accumulation of DNA damage can be detrimental to cell viability because of the enhanced genomic instability, otherwise leading to cellular transformation and tumorigenesis. To maintain genomic integrity, mammalian cells possess multiple DNA repair pathways that recognize and resolve specific types of DNA damage. Among these, nucleotide excision repair (NER) is one of the most important repair pathways for counteracting DNA-damaging agents.

NER is involved in the removal of various helix-distorting DNA adducts that are induced by genotoxic agents [1]. In this process, NER can recognize almost an infinite variety of DNA adducts, including cyclobutane pyrimidine dimers induced by ultraviolet light (UV), covalent DNA adducts formed by carcinogens such as heterocyclic amines (HCAs) and polycyclic aromatic hydrocarbons (PAHs), DNA crosslinks, and oxidative DNA damage from endogenous reactive oxygen species. Accordingly, the disruption of the NER machinery would be expected to enhance the toxic and mutagenic effects of genotoxic agents depending on the downstream pathways that result in cell death or carcinogenesis.
NER is further divided into two sub-pathways, namely, global genomic NER (GG-NER) and transcriptioncoupled NER (TC-NER) (Fig. 1) [2]. GG-NER recognizes and excises DNA adducts from the entire genome, including transcribed and non-transcribed regions. On the other hand, TC-NER is responsible for removing transcription blocking-DNA adducts on actively transcribed genomic loci. In mammalian GG-NER, xeroderma pigmentosum group $\mathrm{C}$ (XPC) is involved in the essential role of the initial damage recognition step [3]. Indeed, pathogenic mutations in the gene encoding XPC result in a cancer-prone phenotype due to defective GG-NER [4]. In contrast, TC-NER is activated by stalling the elongation of RNA polymerase II at the site of the DNA adduct. Subsequently, the key factors, Cockayne syndrome protein A (CSA) and Cockayne syndrome protein $\mathrm{B}$ (CSB), initiate the onset of TC-NER. Following the recruitment of the transcription factor II H (TFIIH) complex to the damaged site, GG-NER and TC-NER engage the same protein components for incision of the DNA adduct, which is followed by gap-filling and ligation in order to complete the process. Because of the differential roles of these NER sub-pathways, the specific disruption of GG-NER or TC-NER allows for the elucidation of the underlying mechanisms of crosstalk between the cytotoxicity and the repair pathway of DNA adducts.

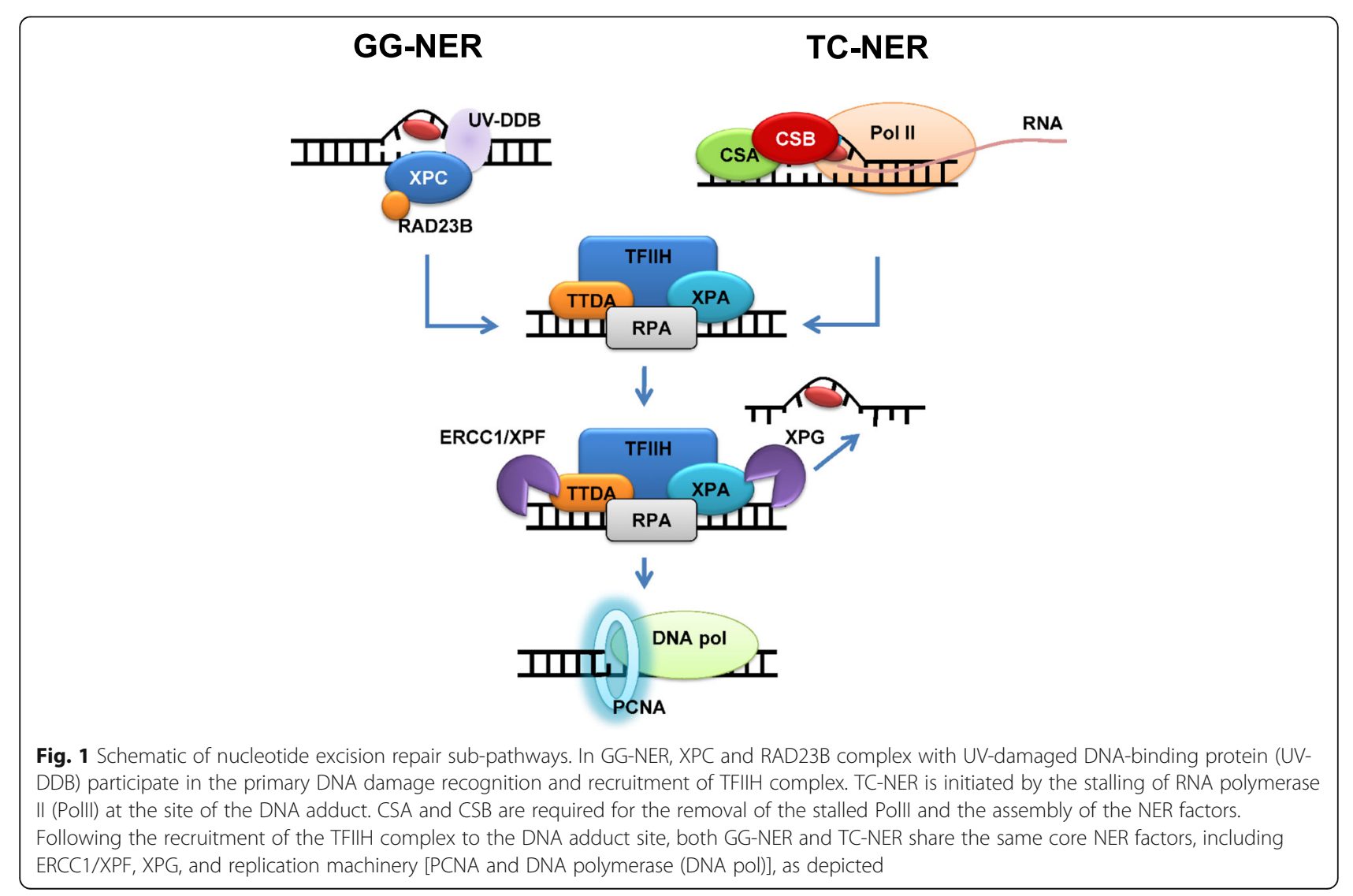


Both GG-NER and TC-NER factors, i.e., XPC and $\mathrm{CSB}$, appear to regulate the role of the tumor suppressor p53. For example, CSB interacts with p53 and stimulates the ubiquitylation of the protein [5], with the loss of CSB resulting in the accumulation of p53 leading to an increased sensitivity of cells to cisplatin $[5,6]$. The ATPase domain of CSB appears important for UVinduced apoptosis [7]. XPC also participates in the process of $\mathrm{p} 53$ degradation through the interaction with MDM2 [8]. In addition, XPC enhances DNA damageinduced apoptosis via downregulation of the antiapoptotic isoform of caspase 2 [9]. Based on these findings, the NER key factors CSB and XPC have been suggested to be involved in the regulation of the equilibrium between the removal of highly damaged cells and the restoration of recoverable cells. Therefore, the pathogenic dysfunction of NER sub-pathways can lead to detrimental effects from exposure to environmental genotoxic agents. However, loss of each NER sub-pathway has revealed a distinct response upon exposure to a genotoxin $[10,11]$, and a phenotypic inconsistency of the NER deficiency has been reported between mice and humans [12]. Thus, the impact of NER sub-pathways on the cytotoxic response to different mutagens in human cells remains to be elucidated.

To better understand the role of NER sub-pathways on the cytotoxicity of genotoxic agents, we developed human lymphoblastoid TK6-isogenic cells lacking the function of XPC or CSB to specifically disrupt GG-NER or TC-NER, respectively. Human TK6 is a standard and widely used cell line for in vitro genotoxicity testing [13]. Using these cells, we comparatively evaluated the cellular sensitivities to genotoxic agents, including ultraviolet $\mathrm{C}(\mathrm{UVC})$, benzo [a] pyrene $(\mathrm{B}(\mathrm{a}) \mathrm{P})$ as $\mathrm{PAHs}$, 2amino-3,8-dimethylimidazo [4,5-f] quinoxaline (MeIQx) and 2-amino-1-methyl-6-phenylimidazo [4,5-b] pyridine (PhIP) as HCAs, $\gamma$-rays that induce DNA strand breaks, and 2-acetylaminofluorene (2-AAF). Our results demonstrated that GG-NER- and TC-NER-deficient TK6 cells are a good tool for clarifying the mechanisms of DNA damage in the cellular response to genotoxic agents.

\section{Materials and methods}

\section{Cell culture}

The human lymphoblastoid cell line TSCER122, an isogenic derivative of TK6, was used in this study [14]. Cells were cultured in RPMI-1640 medium (Nacalai Tesque) with 10\% horse serum (Nichirei Biosciences, Inc.), $100 \mathrm{U} /$ $\mathrm{mL}$ penicillin, $100 \mu \mathrm{g} / \mathrm{mL}$ streptomycin, and $200 \mu \mathrm{g} / \mathrm{mL}$ sodium pyruvate at $37^{\circ} \mathrm{C}, 5 \% \mathrm{CO}_{2}$, and $100 \%$ humidity.

Generation of $\mathrm{XPC}^{/-}$and $\mathrm{CSB}^{-/-}$cells

To generate the $\mathrm{XPC}^{-1-}$ and $\mathrm{CSB}^{-/-}$cells, we designed guide RNA (gRNA) targets for CRISPR/Cas9 genome editing in combination with gene targeting constructs. CRISPR-target sequences are depicted in Fig. 2A. gRNAs were inserted into the $B b s I$ site of the pX330 vector as described previously [15].

For disruption of $X P C$, DNA fragments were obtained by PCR from TK6 genomic DNA using the following primers: 5' -ATTCGAGCTCGGTACGAGGCTTCCTCT GATCATCTAACT-3' and 5'-GCTCGAGGGGGGGC CAGGCCTAGTCACGCCCCTAAAG-3' for the $5^{\prime}$-arm, 5'-GGGAAGCTTGTCGACGAACTGCGCAGCCAGA AATC-3' and 5'-GCTTGCATGCCTGCAGGTTCACT CTAGGCAGAAGGAAC-3' for the $3^{\prime}$-arm. The DT-A$\mathrm{pA} /$ loxP/PGK-neo ${ }^{R}$-pA/loxP vector was provided by the Laboratory for Animal Resources and Genetic Engineering, Center for Developmental Biology, Institute of Physical and Chemical Research, Kobe, Japan. The 5' - and 3 '-arms were introduced into the ApaI and AflII sites of the DT-A-pA/loxP/PGK-neo ${ }^{R}$-pA/loxP or DT-A-pA/ loxP/PGK-hygro ${ }^{R}$-pA/loxP vectors, respectively, by using a GeneArt Seamless cloning kit (Thermo Fisher Scientific). The resulting targeting vectors were named pDTA-XPC-neo ${ }^{R}$ and pDT-A-XPC-hygro ${ }^{R}$. The vectors pX330-gRNA $(6 \mu \mathrm{g})$, pDT-A-XPC-neo ${ }^{R}(2 \mu \mathrm{g})$, and pDTA-XPC-hygro ${ }^{R}(2 \mu \mathrm{g})$ were then transfected into cells by the Neon transfection system (Thermo Fisher Scientific). After $48 \mathrm{~h}$ incubation, cells were seeded into 96microwell plates in the presence of G-418 $(1 \mathrm{mg} / \mathrm{mL})$ and hygromycin $(0.625 \mathrm{mg} / \mathrm{mL})$. Drug-resistant cell colonies were picked 10 days after transfection and subjected to genomic PCR using the following primers: $5^{\prime}$ CTACTGCTACCTAAGCCTCTGTCTG-3' and $5^{\prime}$-C GCCTTCTATCGCCTTCTTGACGAGTTCTT-3' for a targeted allele with neomycin-resistance cassette or $5^{\prime}-\mathrm{C}$ TACTGCTACCTAAGCCTCTGTCTG- $3^{\prime}$ and 5' $^{\prime}$-T GACGGCAATTTCGATGATGCAGCTTGG-3' for a targeted allele with hygromycin-resistance cassette. For disruption of $C S B$, DNA fragments were obtained by PCR using the primers 5 '-ATTCGAGCTCGGTACG ATGCTATAATTTTATTCTGTCCTTC-3' and 5' -GCT CGAGGGGGGGCCAACCTCTGTATAATCGGGGG-3' for the 5'-arm, 5'- GGGAAGCTTGTCGACGCAGC CTTAACCTGCTAGAAGC-3' and 5'-GCTTGCATGC CTGCACTAGAATGTGAGTGCCGCAACT-3' for the 3 '-arm. The mutation of AAG to TAG at codon 337, which mimics the CSB patient mutation (Lys337 $\rightarrow$ stop, K337*) [16], was introduced into the $5^{\prime}$-arm by PCRmediated site-directed mutagenesis. The $5^{\prime}$ - and $3^{\prime}$-arms were then introduced into the ApaI and AflII sites of the DT-A-pA/loxP/PGK-neo ${ }^{R}$-pA/loxP or DT-A-pA/loxP/ PGK-hygro ${ }^{R}$-pA/loxP vectors, respectively, as described above. The resulting targeting vectors were named pDTA-CSB-neo $^{R}$ and pDT-A-CSB-hygro ${ }^{R}$. The vectors pX330-gRNA $(6 \mu \mathrm{g})$, pDT-A-CSB-neo ${ }^{R}(2 \mu \mathrm{g})$, and pDTA-CSB-hygro ${ }^{R}(2 \mu \mathrm{g})$ were then transfected into the cells 

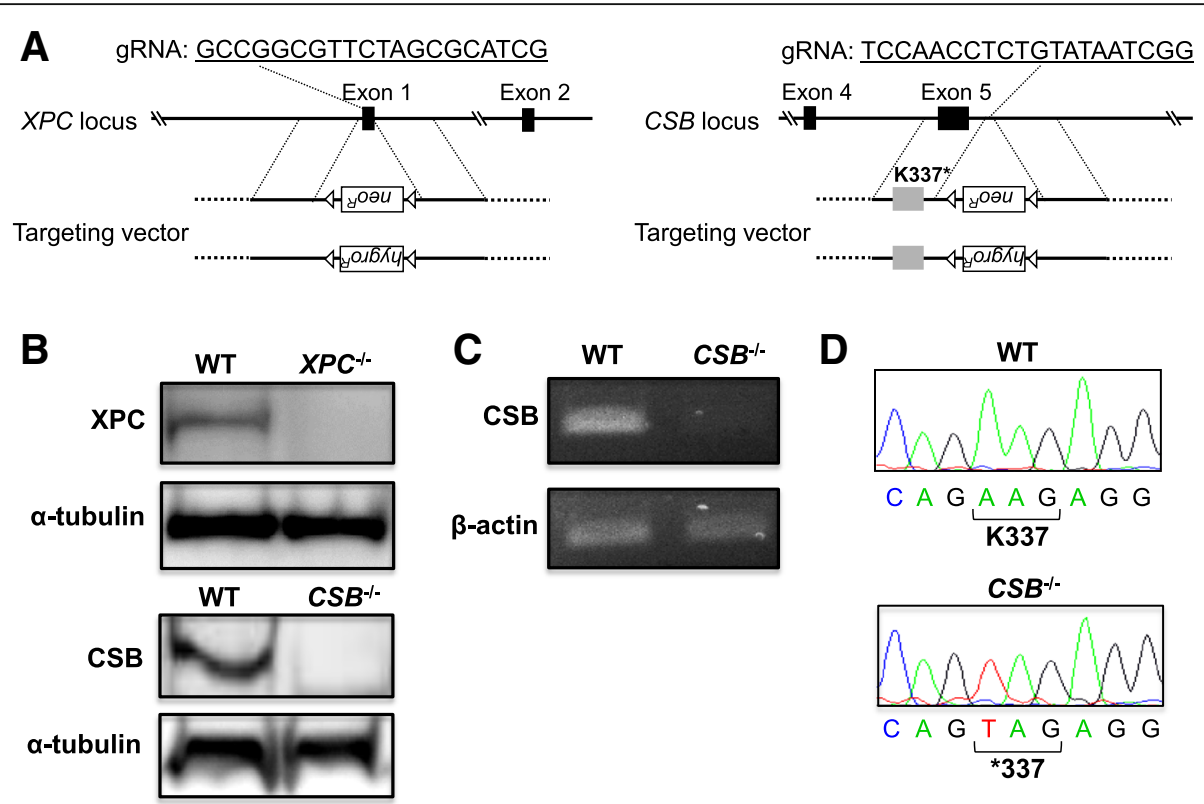

Fig. 2 Generation of $X P C^{-1-}$ and $C S B^{-1-}$ cells. a Schematic representation of the targeted disruption of XPC and CSB. The target sequence of CRISPR/Cas9 and the targeting vector containing a neomycin-resistance $\left(n e o^{R}\right)$ or hygromycin-resistance (hygro ${ }^{R}$ ) marker cassette in the opposite direction are shown. The black boxes and triangles represent the exons and loxP sequences, respectively. $\mathbf{b}$ Western blot analysis for the XPC and CSB proteins. Whole cell extracts of WT, XPC ${ }^{-1}$, and $\mathrm{CSB}^{-1-}$ were loaded onto a 10\% SDS-polyacrylamide gel. a-Tubulin served as a loading control. c RT-PCR analysis for CSB mRNA. The same amounts of total RNA extracted from each cell were used. $\beta$-Actin served as an internal control. $\mathbf{d}$ The sequence of CSB CDNA generated by RT-PCR. The sequences around codon 337 are shown

by the Neon transfection system (Thermo Fisher Scientific). After $48 \mathrm{~h}$ incubation, cells were seeded into 96microwell plates in the presence of G-418 $(1 \mathrm{mg} / \mathrm{mL})$ and hygromycin $(0.625 \mathrm{mg} / \mathrm{mL})$. Drug-resistant cell colonies were picked 10 days after transfection and subjected to genomic PCR using the following primers: 5'-CCTA TCTTTGGATGGCAGAGAGTAT-3' and 5' -CGCCTTC TATCGCCTTCTTGACGAGTTCTT-3' for a targeted allele with neomycin-resistance cassette or 5'-CCTA TCTTTGGATGGCAGAGAGTAT-3' and 5'-TGACGG CAATTTCGATGATGCAGCTTGG-3' for a targeted allele with hygromycin-resistance cassette.

\section{RT-PCR}

Total RNA was extracted from the cells using an RNeasy mini kit (Qiagen). The RNA was then reverse transcribed using SuperScript III Reverse Transcriptase (Thermo Fisher Scientific). Synthesized cDNA was subjected to PCR using the following primers: 5'-GGAGGAGCAGAGGTGAAAATTGAAC-3' and 5'-CTCCTCTGTGG GGAAATACTCAGA-3' for CSB or $5^{\prime}$-GCTCGTCGTC GACAACGGCTC-3' and 5'-CAAACATGATCTGGGT CATCTTCTC-3' for $\beta$-actin. The introduction of the expected mutation into the targeted alleles of the $\mathrm{CSB}^{-/-}$ cells was confirmed by DNA sequencing.

\section{Western blotting}

Total cell extracts were fractioned on 10\% SDSpolyacrylamide gels and subsequently transferred to PVDF membranes. Membranes were blocked with $1 \%$ BSA for XPC or $5 \%$ skim milk for CSB and $\alpha$-tubulin. To detect XPC, CSB, and $\alpha$-tubulin, membranes were incubated with a 1:500 dilution of anti-XPC monoclonal antibody (ab6264, Abcam), 1:200 dilution of anti-CSB polyclonal antibody (H-300, Santa Cruz), or 1:10000 dilution of anti- $\alpha$-tubulin monoclonal antibody (ab7291, Abcam) overnight in Can Get Signal Solution 1 (Toyobo). After washing with phosphate-buffered saline containing $0.05 \%$ Tween 20 , membranes were incubated with a 1:2500 dilution of anti-rabbit IgG conjugated to horseradish peroxidase (GE Healthcare). The chemiluminescent signal was detected using the ECL Prime Western blotting detection reagent (GE Healthcare).

\section{UV irradiation}

Cells were washed and resuspended with RPMI-1640 without phenol red. Cells $\left(2.5 \times 10^{6}\right)$ in $5 \mathrm{~mL}$ medium were exposed to UVC $\left(0,0.5,1.0,1.5\right.$, and $\left.2.0 \mathrm{~J} / \mathrm{m}^{2}\right)$ in $10-\mathrm{cm}$ Petri dishes. Irradiated cells were then seeded into 96-microwell plates at 8 cells $/ \mathrm{mL}$ (1.6 cells/well) to determine cell survival. Colonies in 96-microwell plates were scored after 14 days. 


\section{Chemical treatment}

MeIQx and PhIP were from Wako Pure Chemical Industries Ltd. (Osaka, Japan). B(a)P was purchased from Sigma-Aldrich (St. Louis, MO). 2-AAF was obtained from Tokyo Chemical Industry Co., Ltd. (Tokyo, Japan). All chemicals were dissolved in dimethyl sulfoxide. For cellular exposure to the chemicals, $10 \mathrm{~mL}$ of cell suspensions at a concentration of $5 \times 10^{6}$ cells was treated with chemicals in the presence of rat liver S9 mix (Oriental Yeast Co., Ltd. and BoZo Research Center Inc.) at a concentration of $4.5 \%$ for metabolic activation. After $3 \mathrm{~h}$ of treatment at $37^{\circ} \mathrm{C}$ with gentle shaking, cells were washed with RPMI-1640 medium twice and then seeded into 96-microwell plates as described in the previous section in order to determine cell survival.

\section{Y-Ray irradiation}

$\gamma$-Ray irradiation was performed using a Gammacell 40 Exactor (MDS Nordion, Canada). Irradiated cells were seeded into 96-microwell plates as described in the previous section in order to determine cell survival.

\section{Statistical analysis}

Cell survival was compared between WT, $X P C^{-1-}$, and $\mathrm{CSB}^{-1-}$ cells at the same dose concentrations using Tukey's multiple comparison test. The level of statistical significance was set at $P<0.05$.

\section{Results and discussion}

\section{Generation of $\mathrm{XPC}^{-1-}$ and $\mathrm{CSB}^{-/-}$cells}

To selectively inactivate the NER sub-pathways, XPC and $C S B$ were chosen as the target genes for disruption of GG-NER and TC-NER, respectively. We disrupted $X P C$ using the gene targeting methodology depicted in Fig. 2a. Similarly, we inserted the K337\% mutation in exon 5 of $C S B$ using the same targeting technique. The resulting $\mathrm{XPC}^{-1-}$ and $C S B^{-/-}$cells did not express XPC or the full-length CSB protein, respectively (Fig. 2b). As shown in Fig. 2c, decreased expression of CSB was observed by the introduction of the $\mathrm{K} 37^{*}$ mutations into both alleles of the CSB loci, which may be because of the presence of the nonsense-mediated mRNA decay system in the cells [17]. DNA sequencing of the cDNA revealed that the mutated $\mathrm{mRNA}$ was expressed in the $\mathrm{CSB}^{-1-}$ cells (Fig. 2d). Using these isogenic cell lines, the effect of each NER sub-pathway on the cytotoxicity of various genotoxic agents was then assessed. It should be noted that the treatment of cell lines with S9 mix for metabolic activation did not have a significant effect on the growth and number of colonies formed in the following assay.

\section{Ultraviolet light}

To confirm the contribution of GG-NER and TC-NER to cell survival after UV-exposure, we compared the sensitivity of the WT, $X P C^{-/-}$, and $\mathrm{CSB}^{-/-}$cell lines to UVC irradiation. As shown in Fig. 3a, both $X P C^{-/-}$and $C S B^{-1-}$ cells were considered hyper-sensitive compared with WT. Notably, $X P C^{-/-}$cells displayed a more severe phenotype against UV-induced cytotoxicity than that observed with $\mathrm{CSB}^{-/-}$cells. Previous studies have suggested the differential UV-induced sensitivity of $\mathrm{Xpc}^{-1-}$ and $C s b^{-1-}$ mouse cells depending on the cell-type; $C s b^{-1-}$ mouse embryonic fibroblasts (MEFs) and keratinocytes are highly sensitive to UV irradiation compared with $\mathrm{Xpc}^{-1-}$ cells, but $\mathrm{Xpc}^{-1-}$ embryonic stem cells are more susceptible to UV exposure than $C s b^{-/-}$cells $[18,19]$. In the former case, the enhanced sensitivity of $\mathrm{Csb}^{-1-}$ cells to UV irradiation is likely due to the increased level of apoptotic response in $C s b^{-/-}$cells $[18,19]$. In the latter case, deficiency of $C s b$ results in higher UV-induced mutation rate than $X p c$ deficiency [18], resulting in proliferation of damaged cells. Thus, among the NER subpathways, not only the disruption of CSB, but also the loss of XPC is more detrimental to cellular survival upon exposure to UV in human TK6 cells. The severe sensitivity of the cells to UVC can be because of the role of these NER factors to selectively eliminate highly damaged abnormal cells via apoptosis in humans [9].

\section{B(a)P}

$\mathrm{B}(\mathrm{a}) \mathrm{P}$ is a potent $\mathrm{PAH}$ carcinogen present in tobacco smoke and is formed during the incomplete combustion of organic materials [20]. B(a)P is metabolized to the reactive intermediate benzo [a]pyrene-7,8-dihydrodiol-9, 10-epoxide (BPDE), which forms bulky DNA adducts in cells [21]. In order to define $\mathrm{B}(\mathrm{a}) \mathrm{P}$-induced cytotoxicity, cell survival after exposure to the chemical was determined. Cellular sensitivity to $\mathrm{B}(\mathrm{a}) \mathrm{P}$ was dramatically enhanced by deficiency of $C S B$ [significant at 3 and $6 \mu \mathrm{g} /$ $\mathrm{mL} \mathrm{B}(\mathrm{a}) \mathrm{P}(p<0.01)$ ] (Fig. $3 \mathrm{~b})$. On the other hand, the sensitivity of $X^{-1-}$ cells was only slightly higher than WT, which was significant at $6 \mu \mathrm{g} / \mathrm{mL} \mathrm{B}(\mathrm{a}) \mathrm{P}(p<0.05)$. These results indicated that $X P C^{-1-}$ cells were more resistant to $\mathrm{B}(\mathrm{a}) \mathrm{P}$ compared with $C S B^{-1-}$ cells. It has been shown that exposure of BPDE to human cells induces the upregulation of NER genes, including $X P C, X P F$, $X P G$, and $D D B 2$, in a p53-dependent manner [22]. However, the expression of $C S B$ is not enhanced upon exposure to BPDE [22]. According to these findings and our results, XPC appears to have a major role in eliminating highly damaged cells via DNA damage-induced apoptosis in the absence of TC-NER, as suggested by the previous reports showing that the increased level of apoptotic response in $\mathrm{Csb}^{-/-}$cells, but not in $\mathrm{Xpc}^{-/-}$ mouse cells in response to genotoxic stress [18, 19]. 


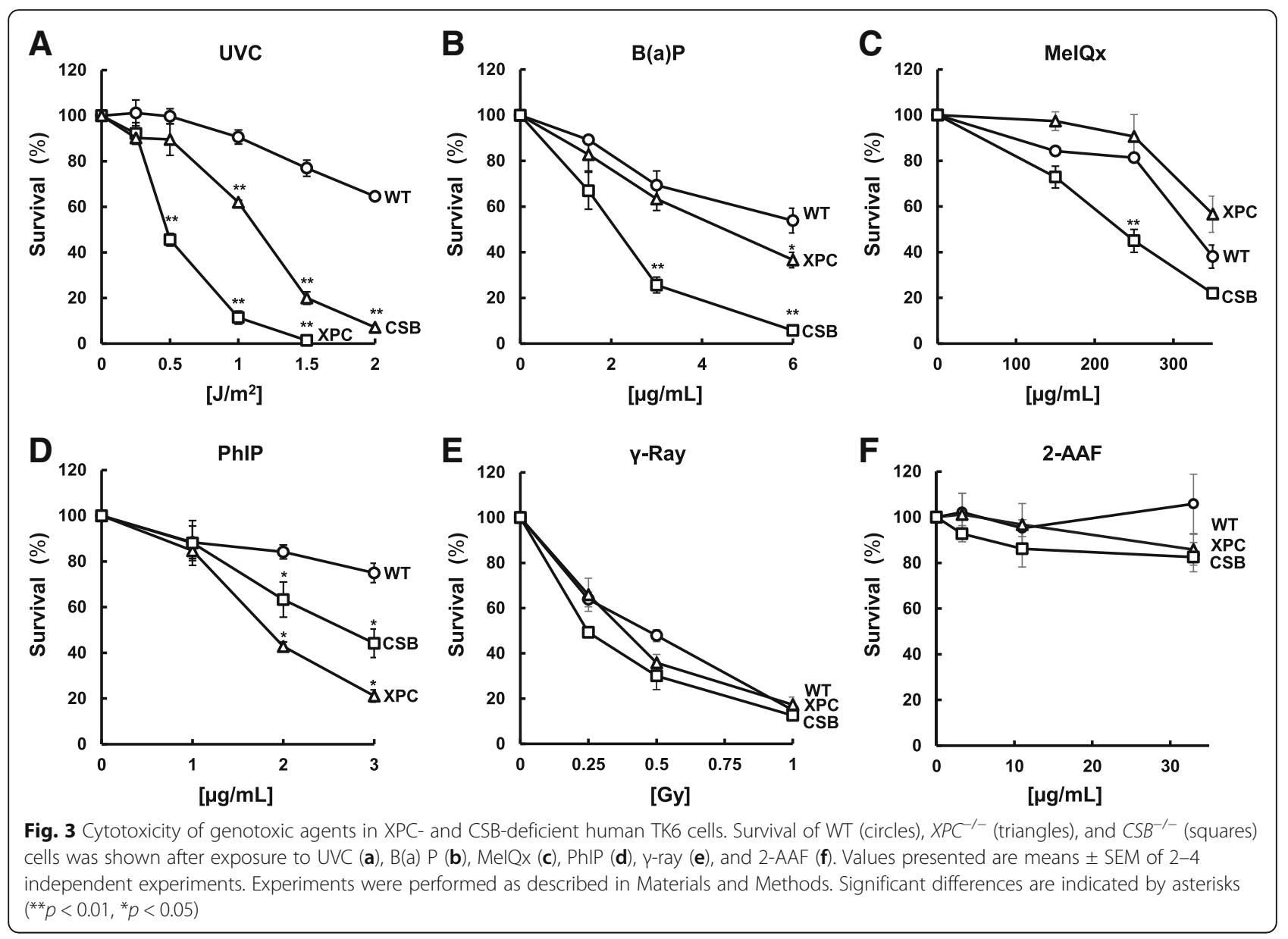

\section{MelQx}

MeIQx is an HCA that is present in cooked meat and fish. We examined the roles of the GG-NER and TC-NER factors in the cellular tolerance to the cytotoxicity of MeIQx. The disruption of CSB significantly sensitized cells to MeIQx at $250 \mu \mathrm{g} / \mathrm{mL}(p<0.01)$ (Fig. 3c). On the other hand, $X P C^{-1-}$ cells were somewhat less sensitive compared with WT, although these differences were not statistically significant at all doses $(150,250$, and $250 \mu \mathrm{g} / \mathrm{mL})$. This observation can be explained by the amount of oxidative DNA damage induced by MeIQx. Upon the exposure of rats to MeIQx at low doses, the formation of bulky MeIQx-DNA adducts has been observed [23]. However, the increasing dosage of MeIQx significantly elevated the level of oxidative DNA damage in tissues in the form of 7 , 8-dihydro-8-oxoguanine (8-oxoG). It should be noted that cells derived from CSB patients have been shown to be hyper-sensitive to oxidative DNA damage [24]. Evidences for the involvement of CSB in the repair of oxidized base damages have also been reported [25-27]. Therefore, enhanced sensitivity in $\mathrm{CSB}^{-/-}$cells and the loss of sensitivity in $X P C^{-1-}$ cells against MeIQx are likely due to both the CSB-mediated repair of oxidative DNA damage and XPC- induced apoptosis in cells. Collectively, the inactivation of TC-NER, but not GG-NER, served to enhance the cytotoxicity of MeIQx in human cells.

\section{PhIP}

PhIP, another HCA and well-known food carcinogen, causes bulky DNA adducts at the C8 position of guanine [28]. Contrary with the other genotoxic agents assessed, $X^{-1-}$ cells displayed the highest sensitivity among the three cell lines against PhIP treatment [significant at 2 and $3 \mu \mathrm{g} / \mathrm{mL}$ PhIP $(p<0.05)$ ] (Fig. $3 \mathrm{~d})$. $C S B^{-/-}$cells revealed an intermediate sensitivity between that of WT and $X P C^{-1-}$. Our results are in contrast to a previous study that found no differences in the toxicity of PhIP treatment with $X p c$ knock-out mice in comparison with wild-type [29]. This discrepancy is possibly due to the importance of GG-NER in humans compared with rodents as reported previously [30]. The exposure of TK6 cells to PhIP induces p53 activation, which is true for other genotoxic agents that form bulky DNA adducts [31]. In the case of PhIP, XPC may play a suppressive role in cell death via a mechanism that includes the degradation of $\mathrm{p} 53$ [8]. Hence, our results indicate that the 
loss of GG-NER is critical to the cytotoxic events following the accumulation of PhIP-DNA adducts. It has been reported that PhIP induces not only bulky DNA adducts but also DNA double-strand breaks (DSBs) [32], arising the possibility that the enhanced toxicity of PhIP in NER-deficient cells may be due to the formation of DSBs upon PhIP treatment. Thus, we further investigated cellular survival following exposure to $\gamma$-rays that induce DSBs.

\section{Y-Rays}

It has been reported that the disruption of the $C s b$ gene sensitizes MEFs to ionizing radiation [33]. A possible involvement of XPC in DSB repair has also been suggested [34]. We therefore assessed whether the loss of XPC and CSB contributes to the cytotoxicity of $\gamma$-ray exposure in human lymphoblastoid cells. Cell viability decreased and was dependent on the increasing dosage of $\gamma$-rays in WT, $X P C^{-1-}$, and $C^{-1-}$ cells (Fig. 3e). Although the sensitivity of $\mathrm{CSB}^{-1-}$ cells against $\gamma$-rays was slightly higher than WT cells, there were no significant differences observed between the cell lines. While CSB and XPC do play some roles in DSB repair, the absence of these NER factors did not have a significant impact on the cytotoxicity of $\gamma$-rays in TK6 cells.

\section{2-AAF}

2-AAF is a mutagenic derivative of fluorene capable of forming bulky DNA adducts [35]. We next examined whether the disruption of $X P C$ or $C S B$ alters 2-AAFinduced cytotoxicity. As shown in Fig. 3f, exposure to 2$\operatorname{AAF}(3.3,11$, and $33 \mu \mathrm{g} / \mathrm{ml})$ did not sensitize $X P C^{-/-}$ and $\mathrm{CSB}^{-/-}$cells. Further increasing dose of 2-AAF resulted in the precipitation in the medium during the chemical treatment period, which was not a reliable assay condition.

\section{Conclusions}

In this study, we assessed the effect of GG-NER and TCNER inactivation on the toxicity induced by several environmental mutagens that form bulky DNA adducts. Remarkably, the NER-deficient cells revealed differential sensitivity from the exposure to genotoxic agents, and this was dependent on the DNA adducts formed and the following repair and/or apoptotic mechanisms to be induced. On the basis of these results, we propose that the GG-NER- and TC-NER-deficient cells established in this study will be useful for investigating the mechanisms involved in the individual stages of chemical toxicity, in combination with standard genotoxicity tests. For example, the correlation between symptoms remains unclear, e.g., neurodegeneration, in CS/XP patients and chronic exposure to environmental chemical contaminants in daily life. Accordingly, these cells provide a tool for assessing the risks of exposure to drugs and chemicals that are associated with NER deficiency. Furthermore, these TK6 isogenic cells enable the tracing of the fate of site-specific DNA damage in the defined locus of the thymidine kinase gene [14, 36, 37]. These methodologies may thus shed light on the detailed protective roles of NER factors against genotoxic agents and contribute to the improved risk assessment of chemicals.

\section{Abbreviations \\ 2-AAF: 2-acetylaminofluorene; 8-oxoG: 7,8-dihydro-8-oxoguanine; B(a)P: Benzo [a]pyrene; BPDE: Benzo [a]pyrene-7,8-dihydrodiol-9,10-epoxide; CPD: Cyclobutane pyrimidine dimers; CSA: Cockayne syndrome protein A; CSB: Cockayne syndrome protein B; DSBs: DNA double-strand breaks; GG- NER: Global genomic NER; HCAs: Heterocyclic amines; MEFs: Embryonic fibroblasts; MelQx: 2-amino-3,8-dimethylimidazo [4,5-f]quinoxaline; NER: Nucleotide excision repair; PAHs: Polycyclic aromatic hydrocarbons; PhIP: 2-amino-1-methyl-6-phenylimidazo [4,5-b]pyridine; TC- \\ NER: Transcription-coupled NER; TFIIH: Transcription factor II H; UV: Ultra violet; XPC: Xeroderma pigmentosum group $C$}

\section{Acknowledgements}

The authors are grateful to Dr. Hiroyuki Sasanuma (Kyoto University) and Dr. Shunichi Takeda (Kyoto University) for helpful comments and discussion. The authors wish to thank Dr. Takashi Yamamoto (Hiroshima University) for providing us with DT-A-pA/loxP/PGK-hygro ${ }^{R}$-pA/loxP. The authors would like to thank Enago (www.enago.com) for the English language review.

\section{Authors' contributions}

$A S, T F, A U, M N, M T, T T-E, M H$, and $M Y$ designed the research and discussed the study. AS, TF, AU, MN, MT, TT-E, and MY performed the experiments and analyzed the data. AS and MY wrote the paper. All authors read and approved the final manuscript.

\section{Funding}

This work was supported by JSPS KAKENHI Grant Numbers 25281022, 16H06306, and 16 K16195. This study was also supported by a Grant-in-Aid for Scientific Research from the Ministry of Health, Labour and Welfare (H30-Food-General-003).

Availability of data and materials

Not applicable.

Ethics approval and consent to participate

Not applicable.

Consent for publication

Not applicable.

\section{Competing interests}

The authors declare that they have no competing interests.

\section{Author details}

'Department of Biology, Graduate School of Science, Chiba University, Chiba 263-8522, Japan. ${ }^{2}$ Tokyo Laboratory, BoZo Research Center Inc, 1-3-11, Hanegi, Setagaya-ku, Tokyo 156-0042, Japan. ${ }^{3}$ Division of Genetics and Mutagenesis, National Institute of Health Sciences, 3-25-26 Tonomachi, Kawasaki-ku, Kawasaki 210-9501, Japan. ${ }^{4}$ Department of Chemistry, Kanagawa Institute of Technology, 1030, Shimoogino, Atsugi, Kanagawa 243-0292, Japan.

Received: 15 May 2019 Accepted: 2 July 2019

Published online: 16 July 2019

\section{References}

1. Kusakabe M, Onishi Y, Tada H, Kurihara F, Kusao K, Furukawa M, Iwai S, Yokoi M, Sakai W, Sugasawa K. Mechanism and regulation of DNA damage recognition in nucleotide excision repair. Genes Environ. 2019;41:2.

2. Iyama T, Wilson DM 3rd. DNA repair mechanisms in dividing and nondividing cells. DNA Repair (Amst). 2013;12:620-36. 
3. Scharer OD. Nucleotide excision repair in eukaryotes. Cold Spring Harb Perspect Biol. 2013;5:a012609.

4. Melis JP, Luijten M, Mullenders LH, van Steeg $H$. The role of XPC: implications in cancer and oxidative DNA damage. Mutat Res. 2011;728: 107-17

5. Latini P, Frontini M, Caputo M, Gregan J, Cipak L, Filippi S, Kumar V, VelezCruz R, Stefanini M, Proietti-De-Santis L. CSA and CSB proteins interact with p53 and regulate its Mdm2-dependent ubiquitination. Cell Cycle. 2011;10: 3719-30.

6. Stubbert $\sqcup$, Smith JM, McKay BC. Decreased transcription-coupled nucleotide excision repair capacity is associated with increased p53- and MLH1independent apoptosis in response to cisplatin. BMC Cancer. 2010;10:207.

7. Balajee AS, Proietti De Santis L, Brosh RM Jr, Selzer R, Bohr VA. Role of the ATPase domain of the Cockayne syndrome group B protein in UV induced apoptosis. Oncogene. 2000;19:477-89.

8. Krzeszinski JY, Choe V, Shao J, Bao X, Cheng H, Luo S, Huo K, Rao H. XPC promotes MDM2-mediated degradation of the p53 tumor suppressor. Mol Biol Cell. 2014;25:213-21.

9. Wang QE, Han C, Zhang B, Sabapathy K, Wani AA. Nucleotide excision repair factor XPC enhances DNA damage-induced apoptosis by downregulating the antiapoptotic short isoform of caspase-2. Cancer Res. 2012;72:666-75

10. Rainey RN, Ng SY, Llamas J, van der Horst GT, Segil N. Mutations in Cockayne syndrome-associated genes (Csa and Csb) predispose to cisplatininduced hearing loss in mice. J Neurosci. 2016;36:4758-70.

11. Boonstra A, van Oudenaren A, Baert M, van Steeg H, Leenen PJ, van der Horst GT, Hoeijmakers JH, Savelkoul HF, Garssen J. Differential ultraviolet-Binduced immunomodulation in XPA, XPC, and CSB DNA repair-deficient mice. J Invest Dermatol. 2001;117:141-6.

12. van der Horst GT, van Steeg H, Berg RJ, van Gool AJ, de Wit J, Weeda G, Morreau H, Beems RB, van Kreijl CF, de Gruijl FR, et al. Defective transcription-coupled repair in Cockayne syndrome B mice is associated with skin cancer predisposition. Cell. 1997:89:425-35.

13. Lorge E, Moore MM, Clements J, O'Donovan M, Fellows MD, Honma M Kohara A, Galloway S, Armstrong MJ, Thybaud V, et al. Standardized cell sources and recommendations for good cell culture practices in genotoxicity testing. Mutat Res. 2016;809:1-15.

14. Yasui M, Kanemaru Y, Kamoshita N, Suzuki T, Arakawa T, Honma M. Tracing the fates of site-specifically introduced DNA adducts in the human genome. DNA Repair (Amst). 2014;15:11-20.

15. Cong L, Ran FA, Cox D, Lin S, Barretto R, Habib N, Hsu PD, Wu X, Jiang W, Marraffini LA, Zhang F. Multiplex genome engineering using CRISPR/Cas systems. Science. 2013;339:819-23.

16. Troelstra C, van Gool A, de Wit J, Vermeulen W, Bootsma D, Hoeijmakers JH. ERCC6, a member of a subfamily of putative helicases, is involved in Cockayne's syndrome and preferential repair of active genes. Cell. 1992;71: 939-53.

17. Baker KE, Parker R. Nonsense-mediated mRNA decay: terminating erroneous gene expression. Curr Opin Cell Biol. 2004;16:293-9.

18. de Waard H, Sonneveld E, de Wit J, Esveldt-van Lange R, Hoeijmakers JH, Vrieling H, van der Horst GT. Cell-type-specific consequences of nucleotide excision repair deficiencies: embryonic stem cells versus fibroblasts. DNA Repair (Amst). 2008;7:1659-69.

19. Stout GJ, Oosten M, Acherrat FZ, Wit J, Vermeij WP, Mullenders LH, Gruijl FR, Backendorf C. Selective DNA damage responses in murine Xpa-/-, Xpc-/and Csb-/- keratinocyte cultures. DNA Repair (Amst). 2005;4:1337-44.

20. Phillips $\mathrm{DH}$, Grover PL. Polycyclic hydrocarbon activation: bay regions and beyond. Drug Metab Rev. 1994;26:443-67.

21. Jeffrey AM, Weinstein IB, Jennette KW, Grzeskowiak K, Nakanishi K, Harvey RG, Autrup H, Harris C. Structures of benzo(a)pyrene--nucleic acid adducts formed in human and bovine bronchial explants. Nature. 1977;269:348-50.

22. Christmann M, Boisseau C, Kitzinger R, Berac C, Allmann S, Sommer T, Aasland D, Kaina B, Tomicic MT. Adaptive upregulation of DNA repair genes following benzo(a) pyrene diol epoxide protects against cell death at the expense of mutations. Nucleic Acids Res. 2016;44:10727-43.

23. Fukushima S, Gi M, Kakehashi A, Wanibuchi H, Matsumoto M. Qualitative and quantitative approaches in the dose-response assessment of genotoxic carcinogens. Mutagenesis. 2016;31:341-6.

24. Dianov G, Bischoff $C$, Sunesen M, Bohr VA. Repair of 8-oxoguanine in DNA is deficient in Cockayne syndrome group B cells. Nucleic Acids Res. 1999;27: 1365-8.
25. Menoni H, Wienholz F, Theil AF, Janssens RC, Lans H, Campalans A, Radicella JP, Marteijn JA, Vermeulen W. The transcription-coupled DNA repairinitiating protein CSB promotes XRCC1 recruitment to oxidative DNA damage. Nucleic Acids Res. 2018;46:7747-56.

26. Tuo J, Chen C, Zeng X, Christiansen M, Bohr VA. Functional crosstalk between hOgg1 and the helicase domain of Cockayne syndrome group B protein. DNA Repair (Amst). 2002;1:913-27.

27. Osterod M, Larsen E, Le Page F, Hengstler JG, Van Der Horst GT, Boiteux S, Klungland A, Epe B. A global DNA repair mechanism involving the Cockayne syndrome $B(C S B)$ gene product can prevent the in vivo accumulation of endogenous oxidative DNA base damage. Oncogene. 2002;21:8232-9.

28. Lin D, Kaderlik KR, Turesky RJ, Miller DW, Lay JO Jr, Kadlubar FF. Identification of N-(Deoxyguanosin-8-yl)-2-amino-1-methyl-6-phenylimidazo $[4,5-b]$ pyridine as the major adduct formed by the food-borne carcinogen, 2-amino-1-methyl-6-phenylimidazo [4,5-b] pyridine, with DNA. Chem Res Toxicol. 1992;5:691-7.

29. Klein JC, Beems RB, Zwart PE, Hamzink M, Zomer G, van Steeg H, van Kreij CF. Intestinal toxicity and carcinogenic potential of the food mutagen 2amino-1-methyl-6-phenylimidazo [4,5-b] pyridine (PhIP) in DNA repair deficient XPA-/- mice. Carcinogenesis. 2001;22:619-26.

30. van der Horst GT, Meira L, Gorgels TG, de Wit J, Velasco-Miguel S, Richardson JA, Kamp Y, Vreeswijk MP, Smit B, Bootsma D, et al. UVB radiation-induced cancer predisposition in Cockayne syndrome group a (Csa) mutant mice. DNA Repair (Amst). 2002;1:143-57.

31. Duc R, Leong-Morgenthaler PM. Role of p53 and mismatch repair in PhIPinduced perturbations of the cell cycle. J Chromatogr B Analyt Technol Biomed Life Sci. 2004;802:183-7.

32. Mimmler M, Peter S, Kraus A, Stroh S, Nikolova T, Seiwert N, Hasselwander S, Neitzel C, Haub J, Monien BH, et al. DNA damage response curtails detrimental replication stress and chromosomal instability induced by the dietary carcinogen PhIP. Nucleic Acids Res. 2016;44:10259-76.

33. de Waard H, de Wit J, Andressoo JO, van Oostrom CT, Riis B, Weimann A, Poulsen HE, van Steeg $H$, Hoeijmakers JH, van der Horst GT. Different effects of CSA and CSB deficiency on sensitivity to oxidative DNA damage. Mol Cell Biol. 2004;24:7941-8.

34. Despras E, Pfeiffer P, Salles B, Calsou P, Kuhfittig-Kulle S, Angulo JF, Biard DS. Long-term XPC silencing reduces DNA double-strand break repair. Cancer Res. 2007;67:2526-34.

35. Poirier MC, True B, Laishes BA. Determination of 2-acetylaminofluorene adducts by immunoassay. Environ Health Perspect. 1983:49:93-9.

36. Honma M, Sakuraba M, Koizumi T, Takashima Y, Sakamoto H, Hayashi M. Non-homologous end-joining for repairing I-Scel-induced DNA double strand breaks in human cells. DNA Repair (Amst). 2007:6:781-8.

37. Honma M, Izumi M, Sakuraba M, Tadokoro S, Sakamoto H, Wang W, Yatagai F, Hayashi M. Deletion, rearrangement, and gene conversion; genetic consequences of chromosomal double-strand breaks in human cells. Environ Mol Mutagen. 2003:42:288-98.

\section{Publisher's Note}

Springer Nature remains neutral with regard to jurisdictional claims in published maps and institutional affiliations.

Ready to submit your research? Choose BMC and benefit from

- fast, convenient online submission

- thorough peer review by experienced researchers in your field

- rapid publication on acceptance

- support for research data, including large and complex data types

- gold Open Access which fosters wider collaboration and increased citations

- maximum visibility for your research: over $100 \mathrm{M}$ website views per year

At $\mathrm{BMC}$, research is always in progress.

Learn more biomedcentral.com/submissions 